\title{
Effects of the Addition of Calcium on the Pseudocapacitance of Ruthenium Oxide Electrodes
}

\author{
Yoshio TAKASU,* Takeshi OHnUmA, Syunsuke MizuTANI, Wataru Sugimoto, \\ and Yasushi MURAKAMI
}

\begin{abstract}
Department of Fine Materials Engineering, Faculty of Textile Science and Technology, Shinshu University (3-15-1 Tokida, Ueda 386-8567, Japan)
\end{abstract}

Received December 4, 2000 ; Accepted March 2, 2001

\begin{abstract}
The electrochemical properties of $\mathrm{Ru}-\mathrm{Ca}-\mathrm{O}_{x} / \mathrm{Ti}$ electrodes prepared by a dip-coating method were evaluated. $\mathrm{A} \mathrm{Ru}$ (40\%)-Ca(60\%)-O $x$ /Ti electrode exhibited high pseudocapacitance of $143 \mathrm{mC} \mathrm{cm}^{-2}$ in an alkaline electrolyte which was 20 times larger than that of $\mathrm{RuO}_{2} / \mathrm{Ti}$. This value was equivalent to $638 \mathrm{~F} \mathrm{~g}^{-1}$ for the $\mathrm{RuO}_{2}$ loaded on the electrode. The present electrodes have a potential for use as electrochemical capacitors.
\end{abstract}

Key Words : Electrochemical Capacitor, Ruthenium Oxide, Calcium Oxide, Pseudocapacitance

\section{Introduction}

Electrochemical capacitors are candidates as highpower density energy-storage devices for vehicles and other electric devices. ${ }^{1 /}$ Ruthenium-based oxide materials have been widely studied owing to their high energy density, high electrical conductivity, rapid reversibility, and chemical stability. ${ }^{2-4)}$ Since ruthenium oxide is expensive and scarce, various approaches have been attempted to minimize the amount of ruthenium in the oxide phase and to obtain higher energy density (charge per mass of $\mathrm{RuO}_{2}$ ). ${ }^{5-9)}$ We have reported that the pseudocapacitance of dip-coated ruthenium oxide electrodes can be enlarged by the addition of transition elements such as Mo, V, or La, etc. ${ }^{5,6,8-11)}$ We report here on the improvement in the pseudocapacitive behavior of ruthenium based electrodes by the addition of calcium which is light and inexpensive.

\section{Experimental}

Oxide-coated electrodes in this investigation were prepared by a conventional dip-coating method. Commercial titanium rods ( $1.6 \mathrm{~mm}$ in diameter, $99.5 \%$ ) were used as the substrate. These rods were etched in $10 \%$ oxalic acid solution at $80^{\circ} \mathrm{C}$ for one hour, washed, and then dried in air. Ethylene glycol solutions of $\mathrm{RuCl}_{3} \cdot n \mathrm{H}_{2} \mathrm{O}$ and $\mathrm{Ca}\left(\mathrm{NO}_{3}\right)_{2}$ was mixed in the required molar ratios. The nominal molar ratios of $\mathrm{Ru}: \mathrm{Ca}$ will be presented in brackets throughout this paper. Titanium rods were dipped into the solution and pulled up at a rate of $1 \mathrm{~mm}$ $\mathrm{s}^{-1}$. The dipped electrodes were dried at $60^{\circ} \mathrm{C}$ and calcined at $450^{\circ} \mathrm{C}$ in a preheated furnace in air for $10 \mathrm{~min}-$ utes. The dip-coating process was repeated 10 times.

A beaker-type electrochemical cell equipped with the working electrode, a platinum mesh counter electrode, and a $\mathrm{Ag} / \mathrm{AgCl}$ reference electrode was used for electrochemical measurements. A Luggin capillary faced the working electrode at a distance of $2 \mathrm{~mm}$. The electrolyte was $1.0 \mathrm{M} \mathrm{NaOH}$ or $0.5 \mathrm{M} \mathrm{H}_{2} \mathrm{SO}_{4}$. The cyclic voltammograms of the electrodes were recorded after a stabilization procedure of the electrodes, typically 200 potential sweep cycles at $500 \mathrm{mV} \mathrm{s}^{-1}$ in the electrolyte. The pseudocapacitance of the electrode per geometric surface area, $q$, was calculated from cyclic voltammograms between $0.1-0.9 \mathrm{~V}$ ( $v s$. RHE) in $\mathrm{NaOH}$ or $0.3-1.1 \mathrm{~V}(v s$. RHE) in $\mathrm{H}_{2} \mathrm{SO}_{4}$ at a scan rate of $50 \mathrm{mV} \mathrm{s}^{-1}$.

The surface morphology of the electrodes were observed with a high-resolution field emission-scanning electron microscope (FE-SEM). The roughness factor (RF) of the electrodes before and after 200 potential sweep cycles were measured by the xenon gas adsorption method with an ultra-high vacuum system. X-ray diffraction (XRD) was utilized for structural analysis.

\section{Results and Discussion}

Figure 1 shows typical steady-state cyclic voltammo-

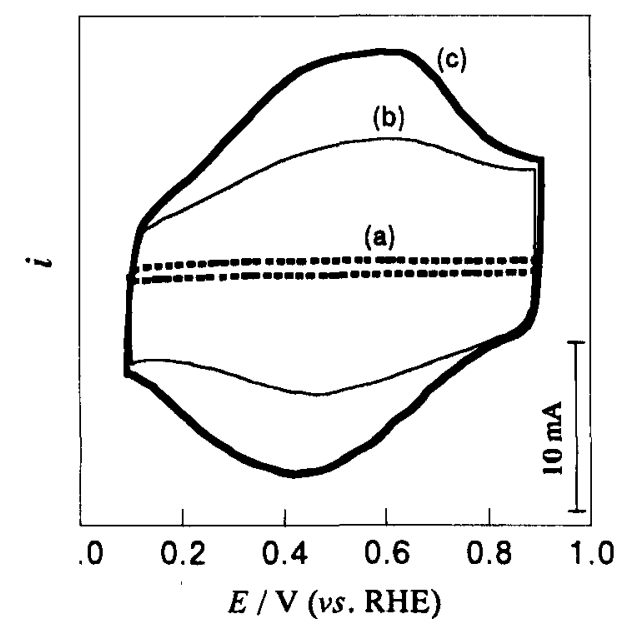

Fig. 1 Steady-state cyclic voltammograms of (a) $\mathrm{RuO}_{2} / \mathrm{Ti}$, (b) $\mathrm{Ru}(50 \%)-\mathrm{Ca}(50 \%)-\mathrm{O}_{x} / \mathrm{Ti}$ and (c) $\mathrm{Ru}(40 \%)-\mathrm{Ca}(60 \%)-\mathrm{O}_{x} / \mathrm{Ti}$ electrodes in $1 \mathrm{M} \mathrm{NaOH}$ at $50 \mathrm{mV} \mathrm{s}^{-1}$. 


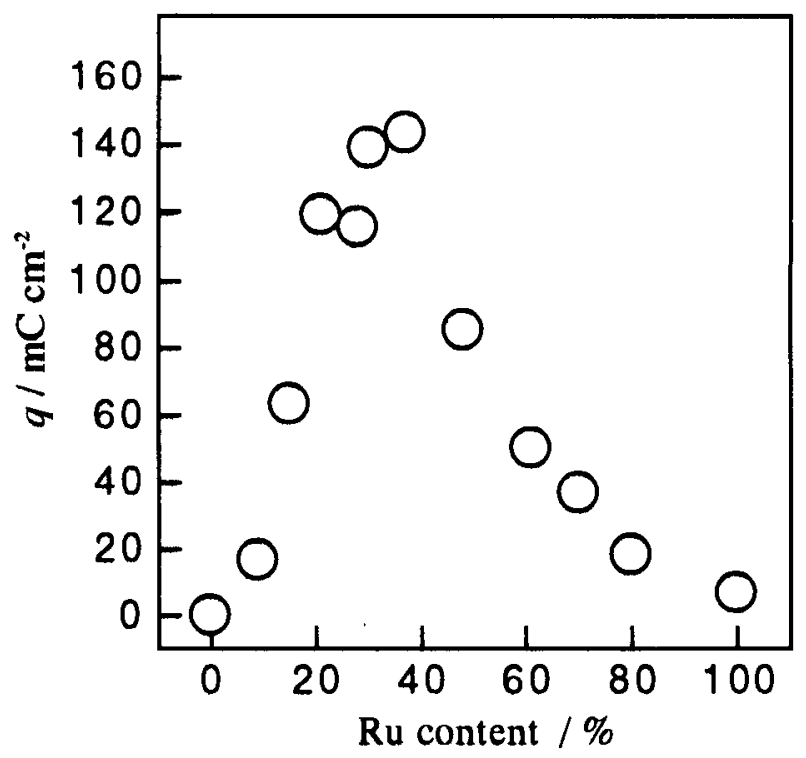

Fig. 2 The relationship between the nominal ruthenium content and the pseudocapacitance per geometric surface area for $\mathrm{Ru}-\mathrm{Ca}-\mathrm{O}_{x} / \mathrm{Ti}$ electrodes.

grams of the $\mathrm{RuO}_{2} / \mathrm{Ti}$ and $\mathrm{Ru}-\mathrm{Ca}-\mathrm{O}_{x} / \mathrm{Ti}$ electrodes. $\mathrm{By}$ the addition of calcium, a clear increase in the pseudocapacitance was observed. The relationship between the ruthenium content and voltammetric charge density, $q$, is shown in Fig. 2. A maximum value of $143 \mathrm{mC} \mathrm{cm}-2$ (255 $\left.\mathrm{F}^{-1}\right)$ was achieved for the $\mathrm{Ru}(40 \%)-\mathrm{Ca}(60 \%)-\mathrm{O}_{x} / \mathrm{Ti}$ electrode, which is roughly 20 times larger than that of $\mathrm{RuO}_{2} / \mathrm{Ti}\left(6.7 \mathrm{mC} \mathrm{cm}^{-2}\right)$. Moreover, this value is equivalent to $638 \mathrm{~F} \mathrm{~g}^{-1}$ for the loaded amount of $\mathrm{RuO}_{2}$.

$\mathrm{XRD}$ revealed that $\mathrm{RuO}_{2}$ and $\mathrm{CaO}$ were present in the as-prepared electrodes as crystalline phases. The surface morphology of the electrodes is shown in Fig. 3. No clear change in the surface morphology was observed in the alkaline electrolyte, even after 200 potential sweep cycles. The roughness factor, $\mathrm{RF}$, of $\mathrm{Ru}(40 \%)-\mathrm{Ca}(60 \%)-$ $\mathrm{O}_{x} / \mathrm{Ti}$ after the electrochemical measurement was $\mathrm{RF}=$ 64 which corresponds to a 1.5 times increase compared to $\mathrm{RF}=40$ for $\mathrm{RuO}_{2} / \mathrm{Ti}$. Since the pseudocapacitance was enlarged by 20 times by the addition of calcium, the enhancement in the electrochemical property can not be due solely to this increase in the roughness. In order to understand the structure of this electrode more clearly, electrochemical measurements were conducted in an acidic electrolyte to dissolve the $\mathrm{Ca}$ species. Figure 3(c) shows the FE-SEM image of the $\mathrm{Ru}(40 \%)-\mathrm{Ca}(60 \%)-\mathrm{O}_{x} /$ Ti electrode after electrochemical measurement in $0.5 \mathrm{M}$ $\mathrm{H}_{2} \mathrm{SO}_{4}$, revealing a porous $\mathrm{RuO}_{2}$ network. Therefore it is suggested that $\mathrm{RuO}_{2}$ was highly dispersed within the $\mathrm{Ca}$ species, resulting in an improvement in the utilization of electrochemically active $\mathrm{RuO}_{2}$.

Despite the porous texture of $\mathrm{Ru}-\mathrm{Ca}-\mathrm{O}_{x} / \mathrm{Ti}$ in an acidic electrolyte, the effect of the addition of calcium on the increase in pseudocapacitance was less-greater than that in the alkaline electrolyte; the electrode (Ru(40\%)-Ca

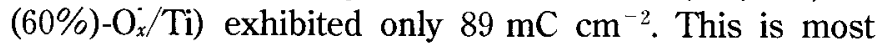
likely due to the stripping off of the active material, $\mathrm{RuO}_{2}$, due to the decrease in mechanical strength when the $\mathrm{Ca}$
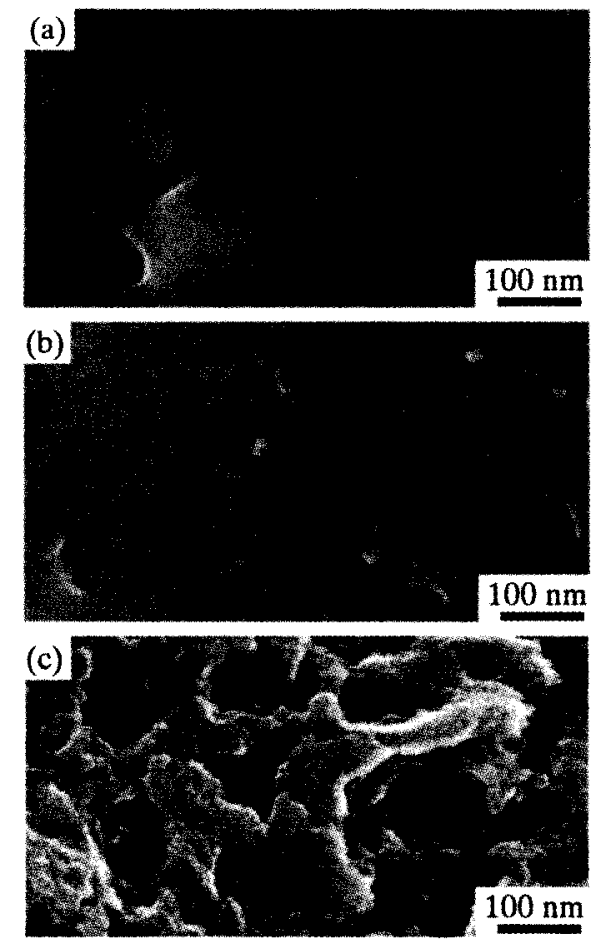

Fig. 3 FE-SEM images of $\mathrm{Ru}(40 \%)-\mathrm{Ca}(60 \%)-\mathrm{O}_{x} / \mathrm{Ti}$ electrodes : (a) before electrochemical measurement and after 200 potential sweep cycles in (b) $1.0 \mathrm{M} \mathrm{NaOH}$ and (c) $0.5 \mathrm{M}$ $\mathrm{H}_{2} \mathrm{SO}_{4}$.

species was leached out into the acidic electrolyte.

\section{Acknowledgements}

The authors are grateful to Permelec Electrode Ltd, Japan, for providing chemical reagents. The present work was supported in part by Grants-in-Aid for Scientific Research (B), Nos. 10450321 and 12793003, from the Ministry of Education, Science and Culture, Japan.

\section{References}

1) B. E. Conway, "Electrochemical Supercapacitors," KluwerPlenum Pub. Co., New York (1999).

2) B. E. Conway, J. Electrochem. Soc., 138, 1539 (1991).

3) O. R. Camara and S. Trasatti, Electrochim. Acta, 41, 419 (1996).

4) T. R. Jow and J. P. Zheng, J. Electrochem. Soc., 145, 49 (1998).

5) Y. Takasu, T. Nakamura, H. Ohkawauchi, and Y. Murakami, J. Electrochem. Soc., 144, 2601 (1997).

6) Y. Takasu, T. Nakamura, and Y. Murakami, Chem. Lett., 1998, 1215 (1998).

7) Y. Murakami, S. Ichikawa, and Y. Takasu, Denki Kagaku (presently Electrochemistry), 65, 992 (1997).

8) Y. Murakami, T. Kondo, Y. Shimoda, H. Kaji, K. Yahikozawa, and Y. Takasu, J. Alloys and Compounds, 239, 111 (1996).

9) Y. Takasu and Y. Murakami, Electrochim. Acta, 45, 4135 (2000).

10) Y. Takasu, Denki Kagaku (presently Electrochemistry), 66, 891 (1998).

11) Y. Murakami, T. Kondo, Y. Shimoda, H. Kaji, X. -G. Zhang, and Y. Takasu, J. Alloys and Compounds, 261, 176 (1997). 